\title{
Medical students' knowledge, attitudes and behaviours related to substance use in Lebanon: a cross-sectional survey
}

Georges Assaf, ${ }^{1}$ Samar Noureddine, ${ }^{2}$ Silva P. Kouyoumdjian ${ }^{3}$ and Jamil El Khoury ${ }^{4}$

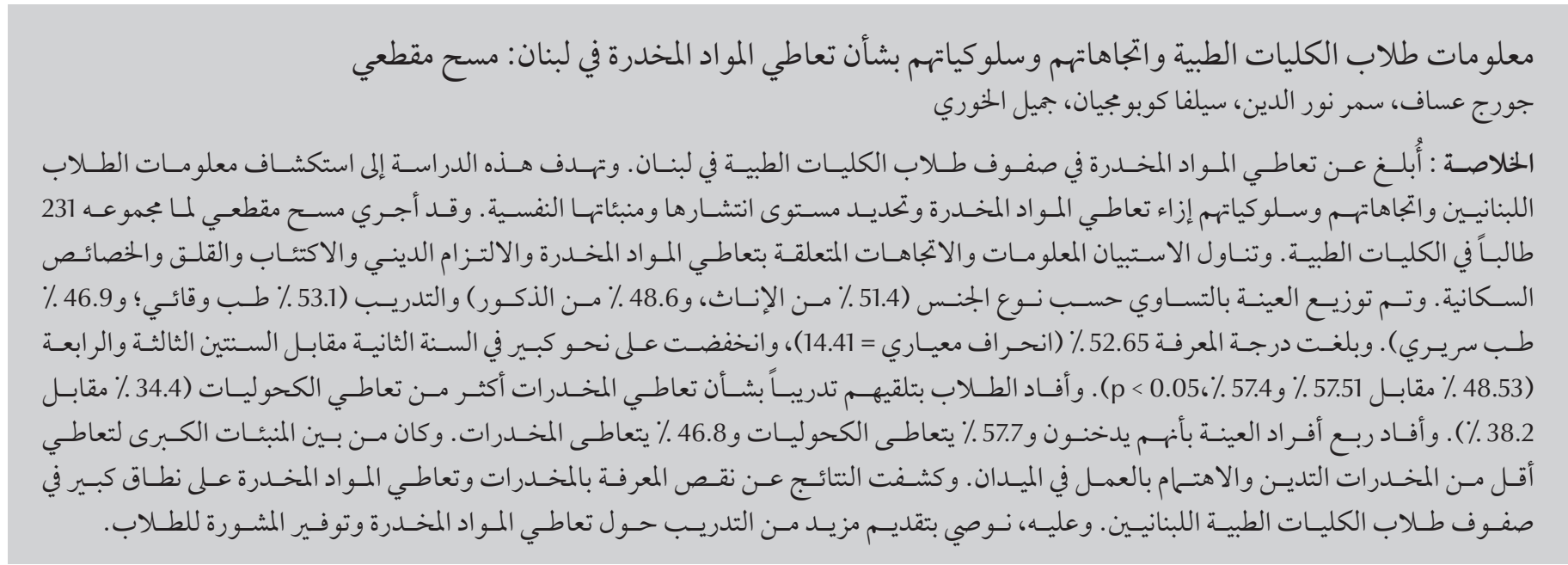

ABSTRACT The study aims were to explore the knowledge, attitudes and behaviours of Lebanese medical students related to substance use and to determine prevalence and psychosocial predictors. A cross-sectional survey of 231 medical students (48.6\% male; 53.1\% preclinical, 46.9\% clinical) was conducted during June 2012-July 2013. The questionnaire addressed knowledge and attitudes about substance use, religiosity, depression, anxiety and demographic characteristics. The knowledge score was $52.7 \%$ (standard deviation 14.4\%), and was significantly lower in 2nd year students (48.53\%) than in $3 \mathrm{rd}$ and 4 th year students $(57.5 \%$ and $57.4 \%)(P<0.05)$. Students reported more training in drug abuse than alcohol abuse (38.2\% vs. 34.4\%). One-fourth reported smoking, 57.7\% using alcohol and 46.8\% using drugs. Significant predictors of lower substance use included intrinsic religiosity and interest in working in the field. The findings reveal inadequate knowledge and considerable substance use in Lebanese medical students. Therefore, training in substance use and counseling of students are necessary.

\section{Connaissances, attitudes et comportements des étudiants en médecine en matière de consommation de substances} psychoactives au Liban : étude transversale

RÉSUMÉ La présente étude vise à explorer les connaissances, les attitudes et les comportements des étudiants en médecine libanais en matière de consommation de substances psychoactives, ainsi qu'à déterminer leur prévalence et les prédicteurs psychosociaux. Une étude transversale auprès de 231 étudiants en médecine (48,6 \% de sexe masculin ; 53,1 \% en études précliniques, 46,9\% en études cliniques) a été conduite de juin 2012 à juillet 2013. Le questionnaire abordait les connaissances et les attitudes en matière de consommation de substances, la religiosité, la dépression, l'anxiété et les caractéristiques démographiques. Le score des connaissances était de $52,7 \%(E T=14,4 \%)$, et était significativement moins élevé en deuxième qu'en troisième et quatrième années $(48,53 \%$ contre $57,51 \%$ et $57,4 \%, p<0,05)$. Les étudiants déclaraient être mieux formés dans le domaine de la consommation de drogues que d'alcool (38,2\% contre 34,4\%). Un quart ont rapporté être fumeurs, 57,7\% être consommateurs d'alcool et 46,8\% de drogues. Les prédicteurs significatifs d'une moins forte consommation de substances incluaient une forte religiosité et un intérêt pour le travail dans ce domaine. Les résultats ont révélé des connaissances insuffisantes et une consommation de substances considérable parmi les étudiants en médecine libanais. Il est donc nécessaire d'organiser une formation dans le domaine de la consommation de substances et de dispenser des conseils aux étudiants.

'Department of Family Medicine, Faculty of Medicine, American University of Beirut, Beirut, Lebanon. ${ }^{2}$ Hariri School of Nursing, American University of Beirut, Beirut, Lebanon (Correspondence to: Samar Noureddine: sn00@aub.edu.lb). ${ }^{3}$ Infectious Disease Epidemiology Group, Weill Cornell Medical College, Qatar. ${ }^{4}$ Senior Research Officer, International Rescue Committee, Beirut, Lebanon.

Received: 28/04/16; accepted: 30/01/17 


\section{Introduction}

The abuse of substances, tobacco, alcohol, stimulants and hallucinogenics, has been an ongoing concern for some time. In the Diagnostic and Statistical Manual 4 (DSM-IV), substance abuse and substance dependence were categorized as 2 separate health problems (1). However more recently, the DSM-V merged them into "Substance use disorders" (2). Diagnostic criteria are presented for use disorder, withdrawal and intoxication for: alcohol; caffeine; cannabis; phencyclidine and other hallucinogens; inhalants; opioids; sedatives, hypnotics or anxiolytics; tobacco; stimulants; and other unknown substances. The criteria for use disorders involve problematic patterns of consumption and impaired control over the amount used, craving, giving up social activities in pursuit of the substance, use despite knowledge of recurrent associated physical and psychological problems, tolerance and withdrawal effects (2).

There is empirical evidence of abuse of alcohol, stimulants and narcotics with some regularity during the course of medical education (3). Substance abuse may lead to dependence problems that can jeopardize careers and relationships, and medical errors that compromise patient safety $(3,4)$. Studies from various countries reported the prevalence of excessive drinking among medical students ranging between $7 \%$ and $45 \%$, and the prevalence of use of drugs such as cannabis and ecstasy ranging between $4 \%$ and $45 \%$ (5-9).

Predictors of substance abuse among medical students include sex, age, family history, academic stress and mental disorders (7,9-12). A study of medical students in Lebanon (13) showed high levels of anxiety (69\%) and depression (28\%), which increase the risk of drug abuse considering the connection between mental health and drug use (2). On the other hand, degree of religiosity was found to be protective against initial alcohol exposure among university students in Lebanon (14). A more recent study of 118 medical residents in Lebanon (15) documented moderate to severe depressive symptoms in $22 \%$, with depression significantly correlated with drug abuse. The investigators reported an illicit drug abuse rate of $14 \%$, with $12 \%$ showing a low level problem and $2.5 \%$ a moderate problem. Over half (59\%) reported drinking alcohol, with $10 \%$ at hazardous levels (15).

Medical education has an impact on how doctors approach substance abuse issues (16). Studies have shown lack of knowledge among medical students and attitudes that could interfere with their care for patients with abuse problems as well as their own wellbeing $(16,17)$. Factors found to contribute to the students' knowledge and attitudes include previous experience with substance use, family history, social and cultural context and exposure to drug education programmes (18). Researchers have highlighted the role of medical education in ensuring that doctors become competent in managing patients with substance abuse. However, some studies have shown that the integration of training in substance abuse management into medical curricula is suboptimal $(19,20)$, leaving physicians unprepared to address these issues in patient care (21). Therefore, measuring students' knowledge and attitudes towards substance use reflects how well medical schools prepare them to address this problem in practice.

In Lebanon, both the French and American systems of medical education are used. The $2 \mathrm{nd}, 3 \mathrm{rd}$ and 4 th years of education in the American system are equivalent to the 5 th, 6 th and 7 th years in the French system. Overall, the substance abuse curriculum does not vary between schools of medicine. The preclinical training years include on average 5 hours of lectures on substance abuse, and the clinical training incorporates a 1-month rotation in psychiatry, which may include exposure to the management of patients with addiction disorders. This indicates the importance of investigating medical students' knowledge and attitude towards substance abuse.

Most of the current research on medical students addresses either substance use with selected predictors or knowledge and attitudes in regard to specific substances. To our knowledge, no published study has comprehensively examined the impact of religiosity, mental health, knowledge and attitudes on the abuse of substances, including alcohol and illicit drugs, among medical students. Thus the aims of this study were to explore the knowledge, attitudes and behaviours of Lebanese medical students related to substance abuse and determine the prevalence and psychosocial predictors of substance abuse in this population.

\section{Methods}

There are 7 medical schools in Lebanon, 6 private and 1 public, all located in Beirut and Mount Lebanon; however, students come from all over the country to these schools. This cross-sectional survey targeted medical students in their last 3 years of study at 1 public and 5 private universities as the 7 th university had not graduated its first cohort at the time of the study. Following approval by the institutional review board of the university where the study was conducted (IRB No. NUR.SN.15), we sent letters to the deans of the faculties of medicine of these 6 universities inviting them to participate in the survey. Two universities did not agree to participate, yielding a sample drawn from 1 public and 3 private universities. The survey was conducted between June 2012 and July 2013.'

Using Godden's formula (22), at least 274 participants were needed to establish 95\% confidence level, considering a finite population and \pm 5 margin of error. Assuming a 50\% response rate 
(5), we sought to recruit at least 509 participants. At the time of the study there were 690 students in the 4 universities in their last 3 years of medical school (2nd, 3rd and 4th in the American system). The number of students per class ranged between 35 and 85 .

All 690 eligible students in the 4 participating universities were sent email announcements about the study from the Dean's office of each medical school. Then a week later questionnaires were sent by regular mail via their university mailboxes, with a covering letter explaining the study and which served as an informed consent document, a return envelope, and instructions to return completed questionnaires to the Dean's office. All the questionnaires were sent in English, as this was the language of instruction in the participating institutions. Reminder emails were sent 1 and 2 weeks later.

The survey included a knowledge and attitudes scale; the Alcohol Use Disorders Identification Test (AUDIT) (23); the Drug Abuse Screening Test (DAST) (24), the Duke Depression and Anxiety scale (DUKE-AD) (25), and the Duke University Religiosity Scale (DUREL) (26). The knowledge and attitude items (17) included 29 multiple choice and true/false knowledge questions and 23 items rated on 3-5 point Likert scales that assessed the attitude regarding substance use. The knowledge items addressed material covered in medical curricula internationally. The attitude items included the participants' perceptions regarding success of treatment, confidence in their ability to treat substance abuse problems, and who can help others with substance use disorders. Substance use was measured using the 10-item AUDIT and the 10-item DAST. A summative score of $8-15$ on the AUDIT indicates "hazardous drinking", 16-19 "harmful drinking" and $\geq 20$ "severe dependence" (23). A DAST score of zero indicates no problem, 1-2 low risk, 3-5 moderate risk, 6-8 substantial risk, and 9-10 severe risk (24). Tobacco smoking was also assessed.

Anxiety and depression were measured using the 7-item DUKE-AD, rated on a 3 point Likert scale (25). A score $\geq 5$ indicates excessive symptoms of anxiety and/or depression. This brief screening instrument was chosen to reduce the research participants' burden. A diagnostic measure was not used since depression and anxiety were not the main outcomes in this study. The 5-item DUREL scale measures organizational and private religious activity and intrinsic religiosity. The DUREL has been used in many large cross-sectional and longitudinal studies worldwide, and is available in 10 languages, including Arabic (26).

The data were analysed using SPSS, version 20.0. Summative scores were calculated for the knowledge, AUDIT, DAST, DUKE-AD and DUREL scales. A cut-off score of $70 \%$ was used to determine whether knowledge was adequate or not (17).

The attitude scale data were analysed per item since they measure different concepts and thus cannot be synthesized into a summative or mean score. Frequencies, percentages, means and standard deviations were used to describe the sample. Sex and class difference for the knowledge, AUDIT and DAST scores as well as the attitude items were analysed using $t$-tests, the non-parametric median test, and analysis of variance (ANOVA) with Bonferroni correction. Since the DAST and AUDIT data were right skewed, Spearman's rho correlation coefficient was calculated between the AUDIT, DAST and the knowledge score, attitude items, DUKE-AD and DUREL scores. Two multiple linear regression analyses were conducted to predict alcohol and drug use. The standard error, $P$-value, and $95 \%$ confidence interval for the regression coefficients were estimated using the bootstrap technique (27). This is a nonparametric statistical technique that can provide more-accurate inferences when the sample size is small or in case assumptions of normality or homoscedasticity are violated. In the bootstrap analysis, 1000 random samples of 231 participants are drawn, with replacement of participants from the original data set. In these samples some participants may be repeated while others may be omitted while keeping the sample size of 231. This 1000 samples are needed for accurate estimation of confidence intervals (27).

\section{Results}

Our sample comprised 231 medical students out of the 690 eligible, a 33.3\% response rate. The average response rates were $47.7 \%$ for 2 nd year students, $21.1 \%$ for 3 rd year students and $31.2 \%$ for 4th year students. Table 1 describes the sample characteristics. There were 194 students (90.3\%) aged under 25 years; the age range was $21-28$ years, mean 23 [standard deviation $(\mathrm{SD})=$ 1.18] years. Around two-thirds of the sample perceived their economic status to be similar to that of their peers; $28.4 \%$ reported attending church or mosque $\geq 1$ time per week and just over half reported engaging in private religious activity $\geq 1$ time per week.

Fifty five students (25.3\%) reported smoking (Table 1). Only 220 students answered the alcohol questions; of those 127 (57.7\%) stated they drank alcohol, including 30 (13.6\%) who drank $\geq 2$ times per week. Forty seven students $(35.6 \%)$ reported consuming $>2$ drinks on a typical day. According to the DAST score, 117 students (53.2\%) had no drug problems; only20 (9.1\%) were at moderate or substantial risk. The DUKE-AD results showed that 126 students (59.7\%) were at risk of anxiety and/or depression. Bivariate analysis using the median test showed men to report significantly higher rates of alcohol use (median AUDIT scores 3 in men vs 1 in women, $P=0.003)$ and drug use (median DAST scores 1 in 


\begin{tabular}{|c|c|c|}
\hline Characteristic & No. & $\% \mathbf{a}$ \\
\hline Age under 25 years & 194 & 90.3 \\
\hline Male & 104 & 48.6 \\
\hline \multicolumn{3}{|l|}{ Year of training } \\
\hline Med II & 101 & 43.7 \\
\hline Med III & 51 & 22.1 \\
\hline Med IV & 79 & 34.2 \\
\hline \multicolumn{3}{|l|}{ Perceived economic status compared to peers } \\
\hline Poorer than most & 21 & 9.9 \\
\hline About the same as most & 138 & 64.8 \\
\hline Richer than most & 54 & 25.4 \\
\hline \multicolumn{3}{|l|}{ Frequency of attending church or mosque } \\
\hline Never & 46 & 21.8 \\
\hline Once/a few times a year & 69 & 32.7 \\
\hline A few times a month & 36 & 17.1 \\
\hline$\geq 1$ time per week & 60 & 28.4 \\
\hline \multicolumn{3}{|c|}{ Frequency of private religious activity (prayer, meditation) } \\
\hline Rarely/never & 59 & 28.0 \\
\hline A few times a month & 40 & 19.0 \\
\hline 1-6 times a week & 72 & 34.1 \\
\hline Daily & 40 & 19.0 \\
\hline Smokes tobacco & 55 & 25.3 \\
\hline \multicolumn{3}{|l|}{ Drinks alcohol ${ }^{b}$} \\
\hline Never & 93 & 42.3 \\
\hline$\leq 1$ time a month & 48 & 21.8 \\
\hline 2-4 times a month & 49 & 22.3 \\
\hline$\geq 2$ times a week & 30 & 13.6 \\
\hline \multicolumn{3}{|l|}{ No of drinks consumed on a typical day when drinking } \\
\hline $1-2$ & 85 & 64.4 \\
\hline $3-4$ & 26 & 19.7 \\
\hline$>5$ & 21 & 15.9 \\
\hline \multicolumn{3}{|l|}{ Drug use screening (DAST) } \\
\hline No problem & 117 & 53.2 \\
\hline Low risk & 83 & 37.7 \\
\hline Moderate level & 15 & 6.8 \\
\hline Substantial level & 5 & 2.3 \\
\hline At risk for anxiety and/or depression (DUKE-AD) & 126 & 59.7 \\
\hline
\end{tabular}

$D A S T=$ drug abuse screening test.

$D U K E-A D=$ Duke Anxiety Depression Scale.

${ }^{a}$ Where there is missing data, a valid percentage is reported.

${ }^{b} n=220$.

men vs 0 in women, $P=0.004$ ). Moreover, a higher AUDIT score was noted among smokers (median 4 in smokers vs 1 in nonsmokers, $P=0.001$ ) but no difference in the DAST score (median in both groups zero, $P=0.924$ ) using the median test.
Ritalin. Over 90\% thought that substance dependence is defined by physiological criteria alone.

One hundred and sixty three students $(70.9 \%)$ knew that heavy alcohol use is associated with hypertension, and 150 (69.4\%) knew the importance of psychological symptoms in the spouse in diagnosing alcoholism (Table 2). However, only 130 students (59.1\%) knew the means of elimination of alcohol and only 38 (17.3\%) knew the effect of abrupt alcohol withdrawal. A total of 186 students (81.6\%) knew that withdrawal from benzodiazepine may cause seizures, but only 72 (32.6\%) knew the acute effect of cannabis. The mean total knowledge score was $52.7 \%$ (SD $=14.4)$; only 22 students (9.5\%) had a total knowledge score $\geq 70 \%$.

Bivariate analysis showed a significant difference in knowledge between the students by class $(F=11.2, P<$ $0.0001)$. Third year students had the highest knowledge score (57.5\%, SD $=13.8$ ), whereas the 2 nd year students had the lowest score $(48.5 \%, \mathrm{SD}=$ 12.7) and the final year students scored $57.4 \%, \mathrm{SD}=15.4$. Second year students had significantly lower scores than $3 \mathrm{rd}$ $(P=0.004)$ and 4 th year students $(P<$ 0.001 ), with the differences being in the knowledge of the classification of some drugs, dependence criteria and alcohol withdrawal. No difference was noted between male and female students in the knowledge score. Knowledge was not significantly correlated to the AUDIT score $(P=0.85)$, but the correlation with the DAST score approached significance (Spearman rho $=-0.12, P$ $=0.088)$.

A total of 86 students (38.2\%) considered that their medical training in alcohol abuse was adequate and 77 (34.4\%) that their training in drug abuse/dependence was adequate; only $66(29.1 \%)$ expressed interest in working in the field (Table 3). Around three-fourths of the participants agreed that the doctor must intervene when patients use substances at hazardous 


\begin{tabular}{|c|c|c|}
\hline \multirow[t]{2}{*}{ Item } & \multicolumn{2}{|c|}{ Correct } \\
\hline & No. & $\%^{\mathrm{a}}$ \\
\hline \multicolumn{3}{|l|}{ Classification of substances } \\
\hline Caffeine & 214 & 93.0 \\
\hline Benzodiazepine & 202 & 87.8 \\
\hline Tobacco (nicotine) & 170 & 73.8 \\
\hline LSD & 147 & 66.5 \\
\hline Dexamphetamine & 147 & 65.3 \\
\hline Alcohol & 114 & 53.0 \\
\hline Methylphenidate (Ritalin) & 96 & 46.6 \\
\hline Dependence on alcohol/drugs is defined by physiological criteria alone & 211 & 91.6 \\
\hline \multicolumn{3}{|l|}{ Alcohol related items } \\
\hline Regular heavy alcohol use is strongly associated with hypertension & 163 & 70.9 \\
\hline Psychological symptoms in the spouse are common in diagnosing alcohol-related problems & 150 & 69.4 \\
\hline Alcohol withdrawal seizures occur within 72 hours after the last drink & 136 & 61.5 \\
\hline Main method of alcohol elimination from the body & 130 & 59.1 \\
\hline Recommended upper limit for women is 21 units/week & 106 & 47.8 \\
\hline Recommended upper limit for men is 6 units on one occasion & 81 & 36.7 \\
\hline Abrupt withdrawal from alcohol is most likely to be fatal & 38 & 17.3 \\
\hline No serious drug interaction occur between alcohol and erythromycin & 39 & 17.3 \\
\hline Someone tolerant of alcohol is likely to be tolerant of benzodiazepines & 102 & 45.7 \\
\hline \multicolumn{3}{|l|}{ Heavy drinking causes elevation in: } \\
\hline Magnesium & 114 & 50.9 \\
\hline MCV & 108 & 48.0 \\
\hline Urea & 93 & 41.3 \\
\hline HDL & 66 & 29.3 \\
\hline \multicolumn{3}{|l|}{ Benzodiazepine-related items } \\
\hline \multicolumn{3}{|l|}{ Benzodiazepine prescription is indicated in: } \\
\hline Alcohol dependence & 137 & 59.6 \\
\hline Depression & 103 & 44.6 \\
\hline Sleep disturbance & 70 & 30.4 \\
\hline Anxiety & 41 & 17.9 \\
\hline Conjunctival injection is an acute pharmacological effect of cannabis & 72 & 32.6 \\
\hline Participants with total knowledge score $>70 \%$ & 22 & 9.5 \\
\hline
\end{tabular}

$\angle S D=$ lysergic acid diethylamide

$M C V=$ mean corpuscular volume.

$H D L=$ high density lipoprotein cholesterol .

${ }^{a}$ Where there is missing data, a valid percentage is reported.

levels but only $28 \%$ agreed that such interventions are rarely successful.

One hundred and thirty three students $(60.2 \%)$ were in favour of physicians self-medicating with legal psychoactive drugs (Table 3), but only 55 (23.7\%) agreed for pharmacists and $<20 \%$ for other health professionals or the public. Only 63 students (29.7\%) agreed that patients with substance abuse problems are readily identified. Over $80 \%$ agreed that the prognosis of patients with dependence is influenced by supportive relationships, the patient's motivation, or appropriate management. A total of 159 students (76.1\%) agreed that the doctor should discuss the alcohol/drug problem with the patient alone (Table 3).
Only 108 students (47.0\%) felt they would be most effective in helping patients reduce alcohol intake (Table 3); the figure for reducing illicit drug use was 97 (42.1\%) and for assisting with quitting smoking 95 (41.4\%). When asked what they would do if they noticed their colleague abusing drugs, 186 students $(80.5 \%)$ reported that they would advise him/her to seek help and 


\begin{tabular}{|c|c|c|c|c|c|c|}
\hline \multirow[t]{2}{*}{ Item } & \multicolumn{2}{|c|}{ Agree/strongly agree } & \multicolumn{2}{|c|}{$\begin{array}{l}\text { Disagree/strongly } \\
\text { disagree }\end{array}$} & \multicolumn{2}{|c|}{ Uncertain } \\
\hline & No. & $\%$ & No. & $\%$ & No. & $\%$ \\
\hline \multicolumn{7}{|l|}{ My medical training was adequate in: } \\
\hline Alcohol abuse/dependence & 86 & 38.2 & 88 & 39.1 & 55 & 24.4 \\
\hline Drug abuse/dependence & 77 & 34.4 & 77 & 34.4 & 70 & 31.3 \\
\hline Interested to work in drug dependence field & 66 & 29.1 & 92 & 40.5 & 70 & 30.4 \\
\hline $\begin{array}{l}\text { The doctor must intervene when patients use alcohol/drugs } \\
\text { at potentially hazardous levels }\end{array}$ & 170 & 75.9 & 29 & 13.0 & 25 & 11.2 \\
\hline $\begin{array}{l}\text { Intervention when alcohol/drugs are used at hazardous } \\
\text { levels is rarely successful }\end{array}$ & 62 & 27.6 & 107 & 47.6 & 56 & 24.9 \\
\hline $\begin{array}{l}\text { A doctor can adequately intervene only when physical } \\
\text { dependence occurs }\end{array}$ & 62 & 27.6 & 101 & 44.9 & 62 & 27.6 \\
\hline $\begin{array}{l}\text { A doctor can responsibly self-medicate with legal } \\
\text { psychoactive drugs }\end{array}$ & 133 & 60.2 & 58 & 26.2 & 30 & 13.6 \\
\hline $\begin{array}{l}\text { A pharmacist can responsibly self-medicate with legal } \\
\text { psycho-active drugs }\end{array}$ & 55 & 23.7 & 133 & 58.0 & 42 & 18.3 \\
\hline $\begin{array}{l}\text { Other health professional can responsibly self-medicate } \\
\text { with legal psycho-active drugs }\end{array}$ & 38 & 16.7 & 60 & 26.3 & 31 & 13.6 \\
\hline $\begin{array}{l}\text { The general public can responsibly self-medicate with legal } \\
\text { psycho-active drugs }\end{array}$ & 27 & 11.7 & 177 & 77.1 & 26 & 11.3 \\
\hline Patients with substance abuse are readily identified & 63 & 29.7 & 86 & 40.6 & 63 & 29.7 \\
\hline \multicolumn{7}{|l|}{$\begin{array}{l}\text { Prognosis of patient with alcohol/drug dependence is } \\
\text { influenced by: }\end{array}$} \\
\hline Supportive relationships & 187 & 85.4 & 17 & 7.8 & 15 & 6.9 \\
\hline Patient's motivation to change & 180 & 82.6 & 16 & 7.3 & 22 & 10.1 \\
\hline Appropriate management & 176 & 80.4 & 16 & 7.3 & 27 & 12.3 \\
\hline \multicolumn{7}{|l|}{$\begin{array}{l}\text { The doctor should discuss the patient's alcohol/drug } \\
\text { problem with: }\end{array}$} \\
\hline The patient alone & 159 & 76.1 & 31 & 14.83 & 21 & 9.1 \\
\hline $\begin{array}{l}\text { The patient and close family, with the patient's } \\
\text { permission }\end{array}$ & 164 & 77.7 & 23 & 10.90 & 24 & 11.4 \\
\hline Patient's motivation is required for intervention & 167 & 80.7 & 24 & 11.6 & 16 & 7.7 \\
\hline How effective do you feel in helping patients: & \multicolumn{2}{|c|}{ Most effective } & \multicolumn{2}{|c|}{ Least effective } & \multicolumn{2}{|c|}{ Neutral } \\
\hline Reduce alcohol intake & 108 & 47.0 & 33 & 15.4 & 81 & 37.7 \\
\hline Reduce illicit drug use & 91 & 42.1 & 46 & 21.3 & 79 & 36.6 \\
\hline Quit smoking & 89 & 41.4 & 56 & 26.0 & 70 & 32.6 \\
\hline
\end{tabular}

a Where there is missing data, a valid percentage is reported.

only $27(11.8 \%)$ stated that they would report him/her to their supervisor. Finally, 187 students $(81.0 \%)$ said that they would reject an offer of stimulants to boost their concentration during exams.

The AUDIT score was significantly correlated with the DAST score (Spearman rho $=0.34, P<0.001)$, perceived adequacy of medical training in alcohol use (rho $=-0.23, P=0.001$ ) adequacy of medical training in drug use (rho = $-0.13, P=0.048)$, interest in working in the field (rho $=-0.23, P=0.001$ ), the doctor must discuss substance use problems with the patient alone (rho $=$ $-0.16, P=0.025)$, and intrinsic religiosity $($ rho $=-0.38, P<0.001)$. Table 4 shows the regression analysis for predicting alcohol use using the significant correlates above, sex and smoking status. Medical training in drug use was not included in the regression due to its high co-linearity with medical training in alcohol use. The model explained $51 \%$ of the variance in alcohol use and the significant predictors were intrinsic 
religiosity, interest in working in the field and drug use (DAST score).

The DAST score was significantly associated with the DUKE-AD score (Spearman rho $=0.15, P=0.033$ ), intrinsic religiosity ( $r$ ho $=-0.20, P=$ $0.004)$, interest in working in the field (rho $=-0.15, P=0.028$ ), and the belief that patient motivation is a prerequisite to intervention success (rho $=0.15, P=$ 0.039).

Table 5 shows the results of the regression analysis to predict drug use using the above significant correlates, AUDIT, sex and knowledge score (since the $P$-value in the bivariate analysis for knowledge was $<0.1$ ). The model explained $44 \%$ of the variance in drug use and the only statistically significant predictor was alcohol use (AUDIT score).

\section{Discussion}

This study examined knowledge and attitudes related to substance use as well as the prevalence and predictors of this behaviour among medical students in Lebanon. The findings reflect low knowledge, some negative attitudes, and rates of drug and alcohol use that raise concern over the wellbeing of these students. The suboptimal knowledge of substance abuse was evidenced by the score $52.7 \%$, which is less than the $70 \%$ cut-off. The low level of knowledge is supported by the finding that the majority of students perceive their medical training to be inadequate and less than half report being effective in helping patients in this area. Although greater knowledge was noted in the 4th year students compared with the 2 nd year ( $57.4 \%$ vs $48.5 \%$ ), final year students still had a score lower than $70 \%$; this compares with the findings of Cape et al. (17), who reported a significant increase in scores from $23.4 \%$ in the 2nd year to $71.8 \%$ in the final year of medical education. In our study, the greatest gaps in knowledge related to alcohol, classification, the upper limit for drinking, alcohol-drug interaction and the effects of heavy drinking, similar to findings by other researchers $(17,28)$. Medical curricula were not examined in this study, nevertheless these findings raise concern about the adequacy of preparation of medical students in managing alcohol abuse.

In terms of attitudes, few findings are worth noting. For instance, students reported high confidence in physicians' ability to manage drug use in themselves and others, while at the same time they did not perceive themselves to be effective in this area. This confidence could predict future behaviour, as in a study of Lebanese medical residents where two-thirds of those with suicidal ideation were self-prescribing psychotropic drugs rather than seeking health care (15). This attitude reflects society's image of doctors as capable of managing any health problem, but raises concerns considering the suboptimal knowledge demonstrated in our sample. Moreover, substance addiction was perceived by the students to be highly influenced by psychosocial factors such as social support and motivation, yet $91.6 \%$ thought that dependence is defined by physiological criteria alone. The uncertainty about whether or not addiction is merely physiological relates to the students' self-perception of being incompetent in treating addiction.

Another interesting finding was the students' report that they would advise their peers who abuse substances to seek help rather than report them to their supervisor; this may be due to the fear of career repercussions of reporting a colleague. Alternatively, these students may not appreciate the seriousness of substance abuse, as was found in a 2014 study on physicians and medical students (29). The findings of low knowledge concur with this explanation, and suggest the need for counselling and a confidential non-punitive mechanism to help medical students with risky behaviours seek psychological support.
Substance use raises concern in this study, especially the positive correlation between alcohol and drug use, a finding consistent with a recent study in Lebanon (15). Alcohol use was significant, with 16\% reporting excessive drinking ( $\geq 5$ drinks), which is more frequent than the prevalence among Turkish (7\%) (5) and Iranian medical students (9\%) (6), but lower than that in the United Kingdom (UK) and the United States of America (USA) $(7,8)$. These differences could be attributed to the effect of religion since the population in Turkey and the Islamic Republic of Iran is mostly Muslim, where drinking is forbidden (17). The multivariate analysis showed intrinsic religiosity to predict lower alcohol intake, supporting this assumption. Religiosity has been found to predict alcohol use by other researchers (14). We did not ask the participants about their religious affiliation since it is considered a sensitive topic and not accepted in our culture. In Lebanon there are Muslims and Christians and the sample probably included both groups. Nevertheless, the rate of alcohol use, which is similar to that reported by Talih et al. in Lebanon (15) raises concern, since poor decision-making (that may result in harm) is positively correlated with heavy drinking (30), and medical students are often faced with challenging decisions. The multiple regression analysis showed that students who are interested in working in the field of substance use were less likely to drink alcohol. Moreover, there was a trend towards lower alcohol use in those who reported that their training was adequate in regard to alcohol use, though this was not statistically significant. On the other hand, drug use was a significant predictor of alcohol use. These findings raise concern given the co-occurrence of drug and alcohol use. Improving medical training in managing alcohol abuse is recommended to improve the students' wellbeing and clinical skills. 


\begin{tabular}{|c|c|c|c|c|c|}
\hline \multirow[t]{2}{*}{ Variable } & \multirow[t]{2}{*}{ B } & \multirow[t]{2}{*}{ SE } & \multicolumn{2}{|c|}{$95 \% \mathrm{Cl}$} & \multirow[t]{2}{*}{$P$} \\
\hline & & & $\begin{array}{l}\text { Lower } \\
\text { bound }\end{array}$ & $\begin{array}{l}\text { Upper } \\
\text { bound }\end{array}$ & \\
\hline Constant & 8.925 & 1.88 & 5.13 & 12.52 & 0.001 \\
\hline Sex & -0.905 & 0.68 & -2.16 & 0.48 & 0.184 \\
\hline Smoking status & 1.249 & 0.91 & -0.53 & 3.09 & 0.164 \\
\hline Intrinsic religiosity & -0.181 & 0.09 & -0.37 & -0.02 & 0.034 \\
\hline Adequacy of training in alcohol abuse & -0.468 & 0.26 & -0.98 & 0.07 & 0.078 \\
\hline Interest in working in the field & -0.732 & 0.27 & -1.25 & -0.21 & 0.004 \\
\hline $\begin{array}{l}\text { The doctor must discuss alcohol/drug dependence } \\
\text { with the patient alone }\end{array}$ & -0.229 & 0.21 & -0.61 & 0.21 & 0.291 \\
\hline DAST score & 2.648 & 0.34 & 1.85 & 3.26 & 0.001 \\
\hline
\end{tabular}

Adjusted $R^{2}=0.51$.

$S E=$ standard error

$\mathrm{Cl}=$ confidence interval.

$D A S T=$ drug abuse screening test

The prevalence of drug use was also alarming at $47 \%$, with $9 \%$ at moderate to substantial risk. The rates were lower than in the USA and UK $(7,8)$, but higher than in Turkey (5). The rate was substantially higher than that reported among Lebanese residents by Talih et al., who used the same measure and reported $14 \%$ drug abuse, with $12 \%$ at low level risk and none at severe level (15). Residents have more responsibility and are expected to experience more stress than generic medical students, who constituted our sample. However, the students in our study may be using drugs to help them in their studying, as reported in a previous study (10); we did not ask what drugs they were using. Another possible explanation is the differences between the study samples: our sample was representative of various geographic regions and social strata, whereas the sample in the study by Talih et al. was more homogeneous, including residents from a single institution only (15). We found that $19 \%$ of our sample would consider or accept an offered stimulant, which raises concern considering the adverse effects of drugs (30).

Alcohol use was the only significant predictor of drug use in the multivariate analysis. Mental health problems did not predict substance use in this sample. However, having two-thirds of the sample at risk for depression or anxiety, similar to prior findings in Lebanon $(13,15)$ and Turkey $(5)$, is worrisome. It is worth noting that the DUKE-AD is only a screening tool and an accurate diagnosis of depression or anxiety requires more validated tools, which may explain the non-significant correlation. Still, the findings suggest the need for further mental health assessment of these students as their mental health problems may increase as they progress in their training and assume more

\begin{tabular}{|c|c|c|c|c|c|}
\hline \multirow[t]{2}{*}{ Variable } & \multirow[t]{2}{*}{ B } & \multirow[t]{2}{*}{ SE } & \multicolumn{2}{|c|}{$95 \% \mathrm{Cl}$} & \multirow[t]{2}{*}{$P$} \\
\hline & & & $\begin{array}{l}\text { Lower } \\
\text { bound }\end{array}$ & $\begin{array}{l}\text { Upper } \\
\text { bound }\end{array}$ & \\
\hline Constant & 0.319 & 0.60 & -0.78 & 1.50 & 0.599 \\
\hline Sex & -0.086 & 0.19 & -0.46 & 0.30 & 0.657 \\
\hline Knowledge & -0.020 & 0.02 & -0.05 & 0.01 & 0.201 \\
\hline Intrinsic religiosity & -0.001 & 0.03 & -0.05 & 0.05 & 0.980 \\
\hline Alcohol use & 0.149 & 0.03 & 0.08 & 0.21 & 0.002 \\
\hline Interest in working in the field & 0.004 & 0.07 & -0.13 & 0.14 & 0.947 \\
\hline Patient motivation is prerequisite for intervention & 0.076 & 0.07 & -0.06 & 0.21 & 0.255 \\
\hline DUKE-AD score & 0.041 & 0.03 & -0.014 & 0.093 & 0.154 \\
\hline
\end{tabular}

Adjusted $R^{2}=0.44$.

$S E=$ standard error.

$\mathrm{Cl}=$ confidence interval.

$D U K E-A D=$ Duke Anxiety Depression Scale. 
responsibility as residents unless they seek help. Furthermore, depression may increase the risk of substance abuse (2). Thus, raising awareness on this issue and providing counselling are needed.

This study had some limitations. First we could not recruit the 274 participants needed according to Golden's formula, but got 231 (84.3\%). Moreover, the study is limited by the low response rate (33.3\%); recruitment was especially low among 3rd and 4th year students, who were difficult to recruit due to their very busy schedules; the under-representation of medical students in their final year of study has been reported by others (17). These factors may have influenced the results, so they ought to be interpreted with caution.
Another limitation stems from the possibility of under-reporting substance use because of social disapprobation. Nevertheless, the reported rates echo those of other investigators (15). Another limitation was our inability to get an overall score for the attitude scale and instead doing analyses per item, which could lead to multiple testing of multiple variables.

In conclusion, this study found knowledge o substance abuse lacking, particularly on alcohol, among medical students, and their perception of the inadequacy of their related medical training along with rates of substance use raise concern. This is a public health issue that must not be underestimated, and medical training on substance abuse needs to be strengthened. For instance, substance use content may be integrated within training using didactic lectures, case-based learning, internships and objective, structured, clinical examination (21). Furthermore, medical students should have access to safe and confidential psychological support, although more-focused investigation of this aspect is required to support this conclusion. This support is 2-fold: it allows students who are abusing substances to have professional support and alleviates the risks associated with depression and anxiety. Such support can protect these students from continued substance abuse in the future.

\section{Funding: None.}

Competing interests: None declared.

\section{References}

1. Diagnostic and statistical manual of mental disorders, 4th ed Washington DC: American Psychiatric Association; 2000.

2. Diagnostic and statistical manual of mental disorders: DSM-5 Washington DC: American Psychiatric Association; 2013.

3. KumarP, Basu D. Substance abuse by medical students and doctors. J Indian Med Assoc. 2000;98(8):447-52. PMID:11294326

4. Tyssen R, Vaglum P, Aasland OG, Gronvold NT, Ekeberg O Use of alcohol to cope with tension, and its relation to gender, years in medical school and hazardous drinking: a study of two nation-wide Norwegian samples of medical students. Addiction. 1998;93(9):1341-9. PMID:9926540

5. Akvardar Y, Demiral Y, Ergor G, Ergor A. Substance use in a sample of Turkish medical students. Drug Alcohol Depend. 2003;72(2):117-21. PMID:14636966

6. Jodati AR, Shakurie SK, Nazari M, Raufie MB. Students' attitudes and practices towards drug and alcohol use at Tabriz University of Medical Sciences. East Mediterr Health J. 2007;13(4):967-71. PMID:17955780

7. Frank E, Elon L, Naimi T, Brewer R. Alcohol consumption and alcohol counselling behaviour among US medical students: cohort study. BMJ. 2008;337:a2155. PMID:18996938

8. Newbury-Birch D, White M, Kamali F. Factors influencing alcohol and illicit drug use amongst medical students. Drug Alcohol Depend. 2000;59(2):125-30. PMID:10891625

9. Horowitz A, Galanter M, Dermatis H, Franklin J. Use of and attitudes toward club drugs by medical students. J Addict Dis. 2008;27(4):35-42. PMID:19042589

10. Kjøbli J, Tyssen R, Vaglum P, Aasland O, Grønvold NT, Ekeberg $\mathrm{O}$. Personality traits and drinking to cope as predictors of hazardous drinking among medical students. J Stud Alcohol. 2004;65(5):582-5. PMID:15536766

11. Tyssen R, Vaglum R. Mental health problems among young doctors: an updated review of prospective studies. Harv Rev Psychiatry. 2002;10(3):154-65. PMID:12023930

12. Shafiq M, Shah Z, Saleem Z, Siddiqi MT, Shaikh KS, Salahuddin $\mathrm{FF}$, et al. Perceptions of Pakistani medical students about drugs and alcohol: a questionnaire-based survey. Subst Abuse Treat Prev Policy. 2006;1:31. PMID:17064420

13. Mehanna Z, Richa S. Prevalence of anxiety and depressive disorders in medical students. Transversal study in medical students in the Saint-Joseph University of Beirut. Encephale. 2006;32(6 Pt 1):976-82. PMID:17372542

14. Ghandour L, Karam E, Maalouf W. Lifetime alcohol use, abuse and dependence among university students in Lebanon: exploring the role of religiosity in different religious faiths. Addiction. 2009;104(6):940-8. PMID:19466919

15. Talih F, Warakian R, Ajaltouni J, Shehab AS. Correlates of depression and burnout among residents in a Lebanese academic medical center: a cross sectional study. Acad Psychiatry. 2016;40:38-45. PMID:26246222

16. Roberts LW, Warner TD, Rogers M, Horwitz R, Redgrave G. Medical student illness and impairment: a vignette-based survey study involving 955 students at 9 medical schools. Compr Psychiatry. 2005;46(3):229-37. PMID:16021594

17. Cape G, Hannah A, Sellman DA. Longitudinal evaluation of medical student knowledge, skills and attitudes to alcohol and drugs. Addiction. 2006;101(6):841-9. PMID:16696628

18. Miller N, Sheppard L, Colenda C, Magen J. Why physicians are unprepared to treat patients who have alcohol- and drug-related disorders. Acad Med. 2001;76(5):410-8. PMID:11346513

19. Isaacson JH, Fleming M, Kraus M, Kahn R, Mundt M. A national survey of training in substance use disorders in residency programs. J Stud Alcohol. 2000;61(6):912-5. PMID:11188498

20. Fang WL, Applegate SN, Stein RM, Lohr JA. The development of substance-abuse curricular content by five North Carolina schools. Acad Med. 1998;73(10):1039-43. PMID:9795618

21. Yoast RA, Wilford BB, Hayashi SW. Encouraging physicians to screen for and intervene in substance use disorders: obstacles and strategies for change. J Addict Dis. 2008;27(3):77-97. PMID:18956531 
22. Godden B. Sample size formulas. Chicago: William Godden [website] 2004 (http://williamgodden.com/samplesizeformula.pdf, accessed 17 June 2017).

23. Babor TF, Fuente JR, Saunders J, Grant M. AUDIT: The Alcohol Use Disorders Identification Test: guidelines for use in primary health care. Geneva: World Health Organization; 1992.

24. Skinner HA. The drug abuse screening test. Addict Behav. 1982;7(4):363-71. PMID:7183189

25. Parkerson GR Jr, Broadhead WE. Screening for anxiety and depression in primary care with the Duke Anxiety-Depression Scale. Fam Med. 1997;29(3):177-81. PMID:9085098

26. Koenig H, Büssing A. The Duke University Religion Index (DUREL): a five-item measure for use in epidemiological studies. Religions. 2010;1(1):78-85.
27. Efron B, Tibshirani RJ. An introduction to the bootstrap. New York: Champan \& Hall; 1993.

28. Granville-Chapman J, Yu K, White P. A follow-up survey of alcohol consumption and knowledge in medical students. Alcohol Alcohol. 2001;36(6):540-3. PMID:11704619

29. Dumitrascu C, Mannes P, Gamble L, Selzer J. Substance use among physicians and medical students. Med Student Res J. 2014;3:26-35

30. Goudriaan AE, Grekin ER, Sher KJ. Decision making and binge drinking: a longitudinal study. Alcohol Clin Exp Res. 2007;31(6):928-38. PMID:17403069 